\title{
Electronic Architecture for a Mobile Manipulator
}

\author{
https://doi.org/10.3991/ijoe.v14i02.7672 \\ Oscar F Avilés S( $\left.{ }^{\varpi}\right)$, Mauricio F Mauledoux M, Oscar G Rubiano M \\ Militar Nueva Granada University (UMNG), Bogotá, Columbia \\ oscar.aviles@unimilitar.edu.co
}

\begin{abstract}
A mobile manipulator is a robotic system consisting of a mobile platform on which a manipulator arm is mounted, allowing the robotic system to perform locomotion and manipulation tasks simultaneously. A mobile manipulator has several advantages over a robot manipulator which is fixed, the main advantage is a larger workspace. The robots manipulators are oriented to work collaboratively with the human being in tasks that simultaneously require mobility and ability to interact with the environment through the manipulation of objects. This article will present the electronic design for a mobile robot manipulator with five degrees of freedom and a 6-wheel traction with four of these directional.
\end{abstract}

Keywords-mobile manipulator, robotic system, electronic design.

\section{Introduction}

A Mobile Manipulator is a system subject to its kinematic restrictions and the degrees of freedom of the manipulator arm mounted on it. These systems combine the advantages of mobile platforms and robotic arms and reduce their disadvantages, for example, a mobile manipulator has a larger working space when it has a mobile platform, as it offers more functionality during operation[1]. Nowadays, movement planning and control of these systems have attracted a lot of attention due to their usefulness. The control of the mobile manipulators mainly includes two aspects: movement planning, both for the mobile platform and the manipulator, and the other, coordinated control of both. Once you have these two, the next thing is to assign the task. In many cases mobilizing the manipulator results in kinematic redundancy, this can be solved by coordinating the platform and the manipulator. The type of coordination to be used will depend on the specificities of the task [2].

This article will present the electronic design for a mobile robot manipulator with five degrees of freedom and a 6-wheel traction with four of these directional. Section II will show a series of robotic platforms showing the previous work on mobile manipulators. Section III describes the design specifications of the manipulator robot in order to realize the electronic architecture. Section IV briefly describes the selection of the actuators required for the robot's drive and manipulator operation. Section V shows the proposed architecture. Finally, section VI and VII conclusions and acknowledgements. 


\section{Previous work}

Some of the most important applications of mobile manipulators are: performing tasks involving explosives, hazardous environments such as outdoor exploration, space operations, construction, military tasks and personal service. The applications of robotic systems in hazardous environments have a high spectrum and their solutions are equally varied. In general many applications include specific challenges associated with the uncertainty and nature of the tasks to be performed. Amongst different tasks there is the task of demining, which consists of eradicating antipersonnel mines or handling explosives, this task has a high humanitarian impact. On the other side, there is the handling of hazardous materials such as radioactive materials, corrosive or highly polluting materials, for which there is a risk if an operator performs these tasks[3]. Below you will find some developments of mobile manipulators.

Figure 1 shows a prototype developed by Worcester Polytechnic which is an intelligent explosive ordnance destruction robot that provides government institutions with a cost-effective and efficient robotic platform. The robot's key features include an intuitive user interface that provides additional sensor feedback and improved visual knowledge compared to existing systems, a three-degree freedom on-board manipulator arm that provides an expanded workspace and a handy gripper that allows object manipulation. Flexible and modular robot design utilizes commercially available components ready to be easy to maintain and repair. [4].

Among its electronic elements are 2 hub-type motors that allow motor traction, linear motors in the manipulator, 3 IP cameras, a wireless communication system and an embedded National Instruments system that allows the handling of other electronic components. A simplified scheme of the system components is shown in Figure 2.

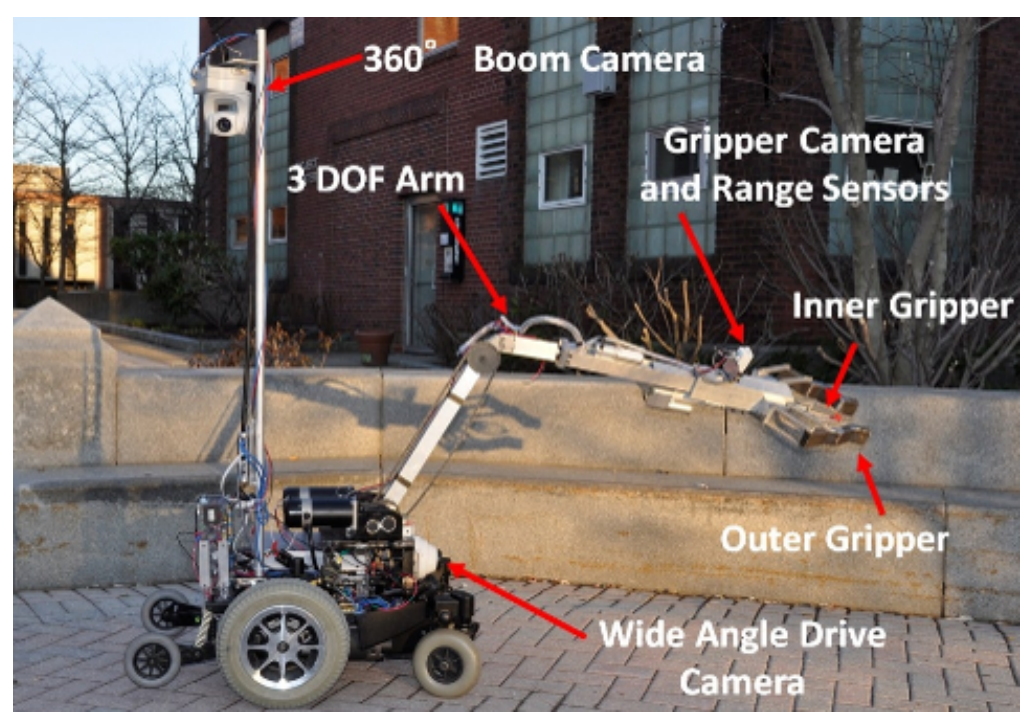

Fig. 1. Worcester Polytechnic Institute - prototype[4] 
Figure 3 shows a low-cost explosive disposal robot (EOD) that emerged from a collaboration between Villanova University (VU) and the Golden West Humanitarian Foundation (GWHF) designed for use in Southeast Asia. This prototype has two cameras (one camera in the gripper and one camera on a post for panoramic view), a two-degree arm (2DOF) with a gripper and a wheel drive system. Figure 4 shows a base station that allows wireless control and the control system (within the robot body) that takes advantage of low-cost, yet powerful electronic components, motor controllers and other devices [5].

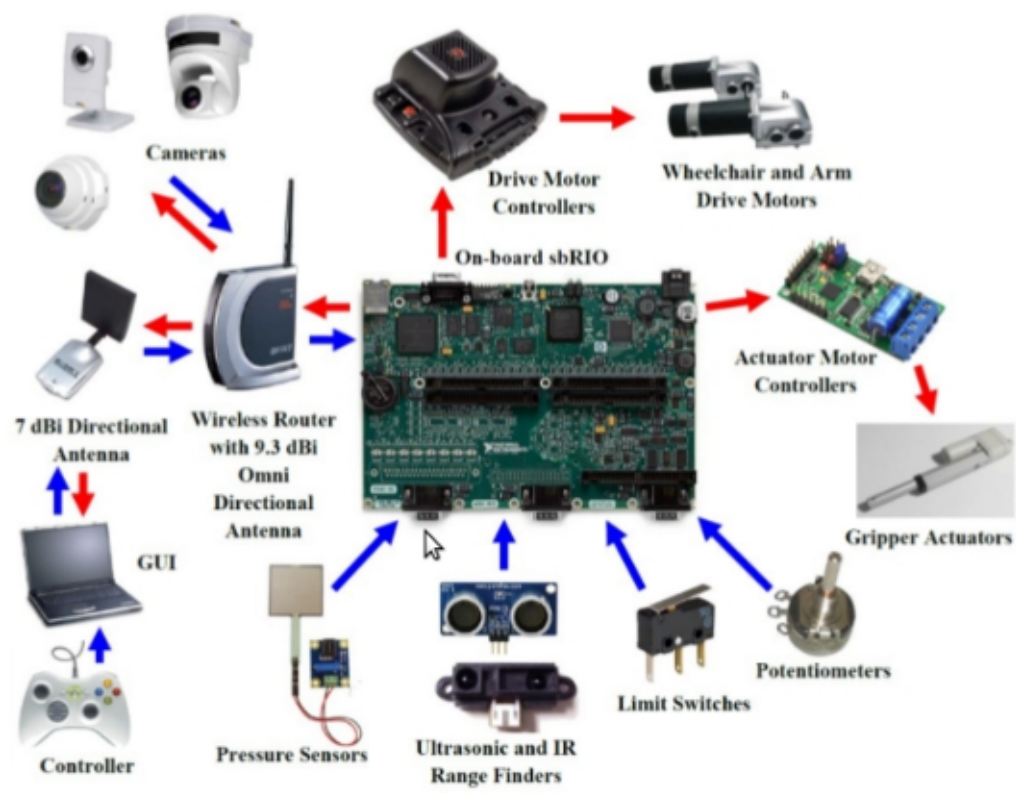

Fig. 2. Electronic robot architecture of the Worcester Polytechnic Institute

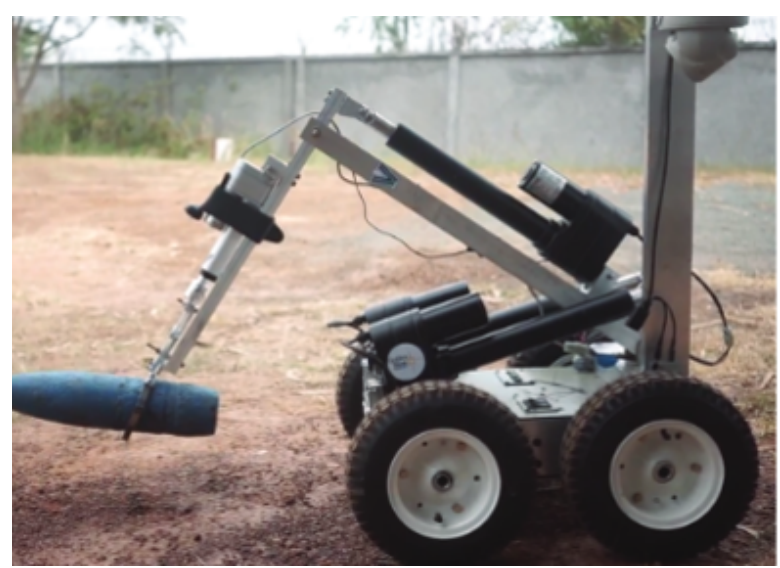

Fig. 3. Golden West Humanitarian Foundation - prototype 


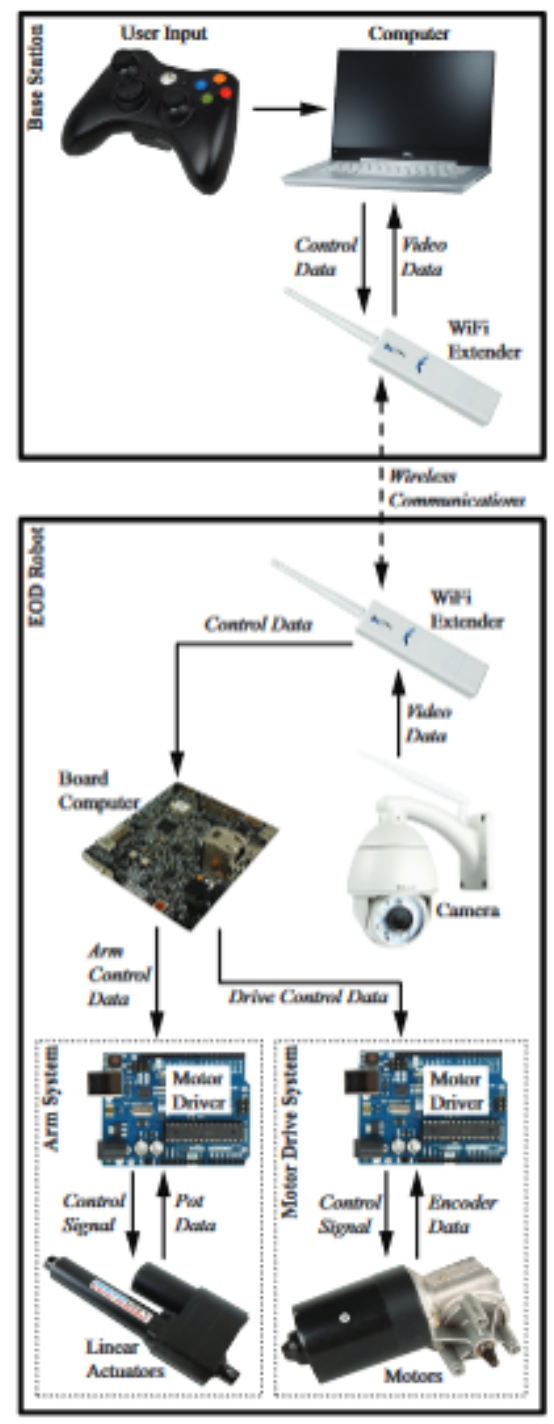

Fig. 4. Golden West Humanitarian Foundation - Electronic scheme

On the other hand, the DAVINCI group of the Nueva Granada Military University has developed a mobile robotic platform called VALI, as shown in Figure 5, for the transport and handling of a disruption cannon through unstructured terrain. This cannon is implemented with the aim of neutralizing explosive devices in rural areas. The mechanical design of the robotic platform is made up of a tracked locomotion system, to be moved on terrain with obstacles not exceeding $3 / 4$ of the wheel diameter. In addition, it has an anthropomorphic manipulator arm for the manipulation of the cannon that composes it [6]. 


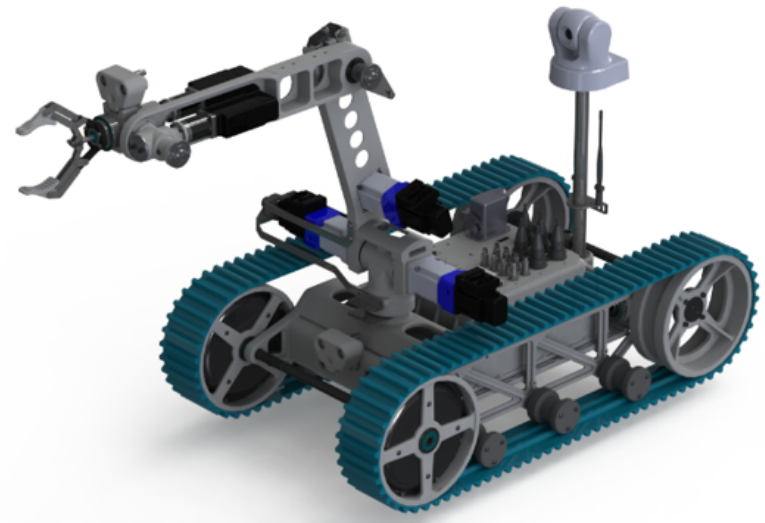

Fig. 5. VALI ROBOT

\section{Robot description}

As can be seen in Figure 6, the designed manipulator robot is a robot that has its rover-type traction that allows the platform to balance and overcome obstacles greater than $10 \%$ of the height of the wheels, each wheel has a motor that allows traction and can allow the platform of $9 \mathrm{~km} / \mathrm{h}$ with a weight of $60 \mathrm{~kg}$, it also has steering motors on the four outer wheels. It also has a 4 degree manipulator of freedom, allowing that in the last link there is a decoupling, which allows to place different tools such as a gripper or a disruptor cannon like the one designed in the previous versions of the VALI robot, Table I shows the robot's main specifications, which will allow the design of the electronic system, component selection and selection of the actuators for traction and manipulator.

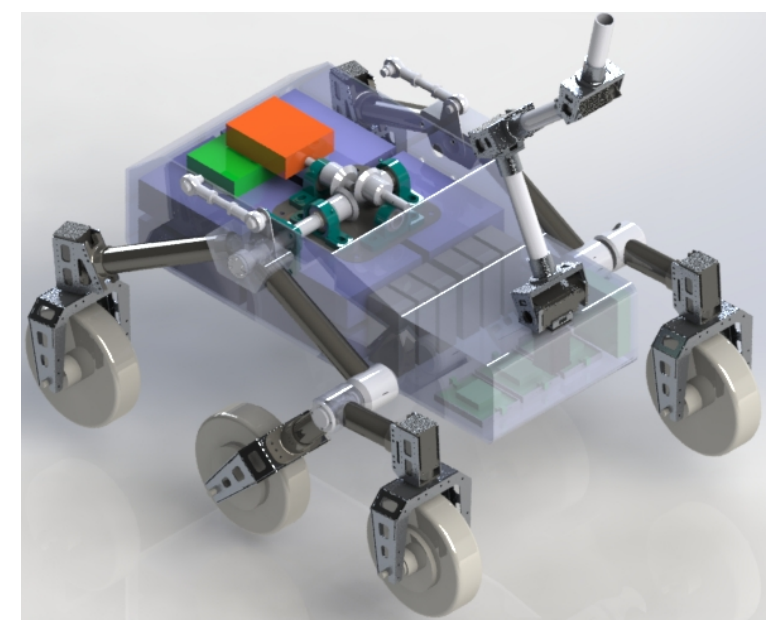

Fig. 6. CAD model of the robot manipulator VALI-3 
Table 1. Especificaciones de diseño

\begin{tabular}{ll}
\hline DESCRIPTION & PARAMETERS \\
\hline \hline Weight & $60 \mathrm{~kg}$ \\
\hline Dimensions & $1 \mathrm{~m} \times 1 \mathrm{~m} \times 1 \mathrm{~m}$ \\
\hline Traction Type & Tipo rueda \\
\hline Autonomy & $2-3 \mathrm{~h}$ \\
\hline Communication system & Wifi $-100 \mathrm{~m}$ \\
\hline Manipulator & Three links $(6 \mathrm{DOF})$ \\
\hline Self Recovery System & Programmable \\
\hline Type of terrain & $0 \mathrm{~cm}$ height and $45^{\circ}$ inclinations \\
\hline Speed & $9 \mathrm{~km} / \mathrm{h}$ \\
\hline
\end{tabular}

\section{$4 \quad$ Selection of actuators}

This section will show the selection of required actuators and power supplies that allow the robot an operating time of 2 hours.

\subsection{Traction motors}

Based on the experience acquired in previous research projects, it was decided to use HUB engines, which have $70 \mathrm{Nm}$ which give their power to move the $60 \mathrm{Kg}$ specified in the robot. Based on the maximum power that the motors $(P)$ and the operating voltage $(V)$ can consume, the current required for continuous operation during two hours of continuous operation and the total consumption $\left(C_{f}\right)$ is calculated.

$$
\begin{gathered}
P=400 \mathrm{~W} ; V=48 \mathrm{~V} ; I=\frac{P}{V} ; I=\frac{400 \mathrm{~W}}{48 \mathrm{~V}}=8,33 \mathrm{~A} \\
C_{f}=I \cdot T=8,33 \mathrm{~A} \cdot 2 \mathrm{~h}=16,66 \mathrm{Ah}
\end{gathered}
$$

As a precautionary measure preventing the batteries from being completely discharged, which can lead to a decrease in capacity and/or loss of capacity, it is over dimensioned in such a way that the necessary consumption is $80 \%$ of the total battery capacity.

$$
C_{f}=16,66 \mathrm{Ah} / 0,8=20,825 \mathrm{Ah}
$$

Therefore a battery of $20 \mathrm{Ah}$ to $48 \mathrm{~V}$ would be needed for each motor.

\subsection{Direction Motors.}

To calculate the torque in order to select the steering motors, it is necessary to analyze the contact surface of the rim on the surface to be moved. Figure 7 shows the 
free-body diagram of the forces that affect the tire when the tire is deformed on the contact surface.

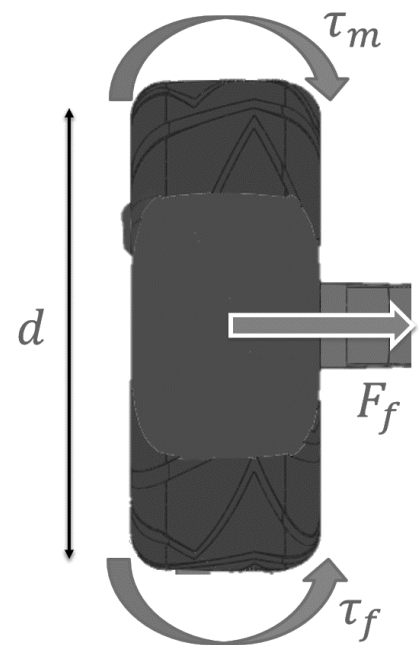

Fig. 7. Contact surface between rim and floor

Where $\tau_{m}$ is the torque produced by the direction motor, $\tau_{f}$ is the torque produced by friction force, $F_{f}$ is the force produced by contact between the rim and the contact surface and $d$ is the length of the tire deformation.

The calculations presented here are estimates, since they depend on the deformation of the rim and this depends on actors that are dynamic due to changes in temperature, internal pressure, tire material and contact surface.

$$
\begin{gathered}
F_{f}=F_{\mu} \cdot N=0,9 \cdot 15 \mathrm{Kg} \cdot 9,8 \frac{\mathrm{m}}{\mathrm{s}} \\
T_{f}=F_{f} \cdot \frac{d}{2}=132,3 \mathrm{~N} \cdot \frac{0,04}{2} \mathrm{~m}=2,646 \mathrm{Nm}
\end{gathered}
$$

This determines that in order for the rim to change direction, a torque greater than $2,646 \mathrm{Nm}$ must be applied for the case study. For ease of operation and variety in its characteristics it is decided to use dynamixel motors pro H54-200-S500-R which are engines that have a torque in continuous operation of $44.2 \mathrm{Nm}$.

Based on this and making use of the manufacturer's data sheet, Figure 8 , the current that the actuator uses according to its load is calculated, this with the approximate values that allow choosing a feeding system for a specified operating time.

Assuming that a constant torque of $8.5 \mathrm{Nm}$ is required, the current required according to the table is $2.5 \mathrm{~A}$. Having these variables, we proceed to make the calculations for the 4 batteries as shown below, where $I$ is the total current consumed 
by the four motors needed to give direction to the engine and $C$ is the total consumption of the motors in 2 hours of estimated operating time in continuous use.

$$
T_{m}=8,5 \mathrm{~A} ; I_{m}=2,5 \mathrm{~A} ; I_{m T}=2,5 \mathrm{~A} \cdot 4=10 \mathrm{~A} ; C_{T}=10 \mathrm{~A} \cdot 2 \mathrm{~h}=20 \mathrm{Ah}
$$

With this information, a $48 \mathrm{~V}$ and $20 \mathrm{Ah}$ lithium polymer battery is selected, which will support the 4 steering motors energetically.

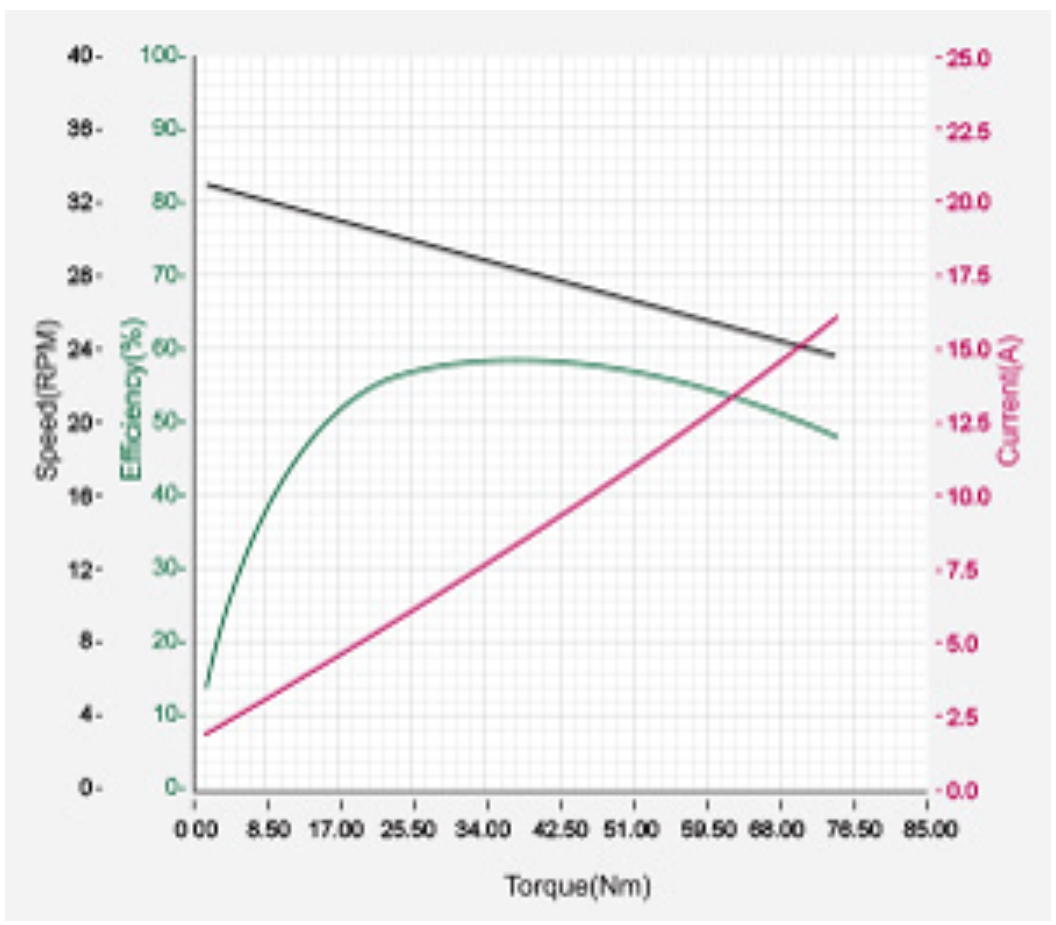

Fig. 8. Torque Chart

\section{Proposed architecture}

The system is composed by four ip cameras (one in the back, one in the front, one in the griper and a robotic panoramic), with the purpose of being a teleoperated system from a remote station, for this reason there is also a wifi communication system that allows a range of $100 \mathrm{~m}$ in a direct line. Also as a central core, there is a Fitpc system in which the control algorithms of the platform are located, two usb2dynamixels are connected to it, which allow the manipulator actuators and the robot direction to be controlled and finally an embedded STM32F4 system which allows real-time processing and is in responsibility of reading the encoder data, generating the pwm for each wheel, rotation change signal of the motors. 


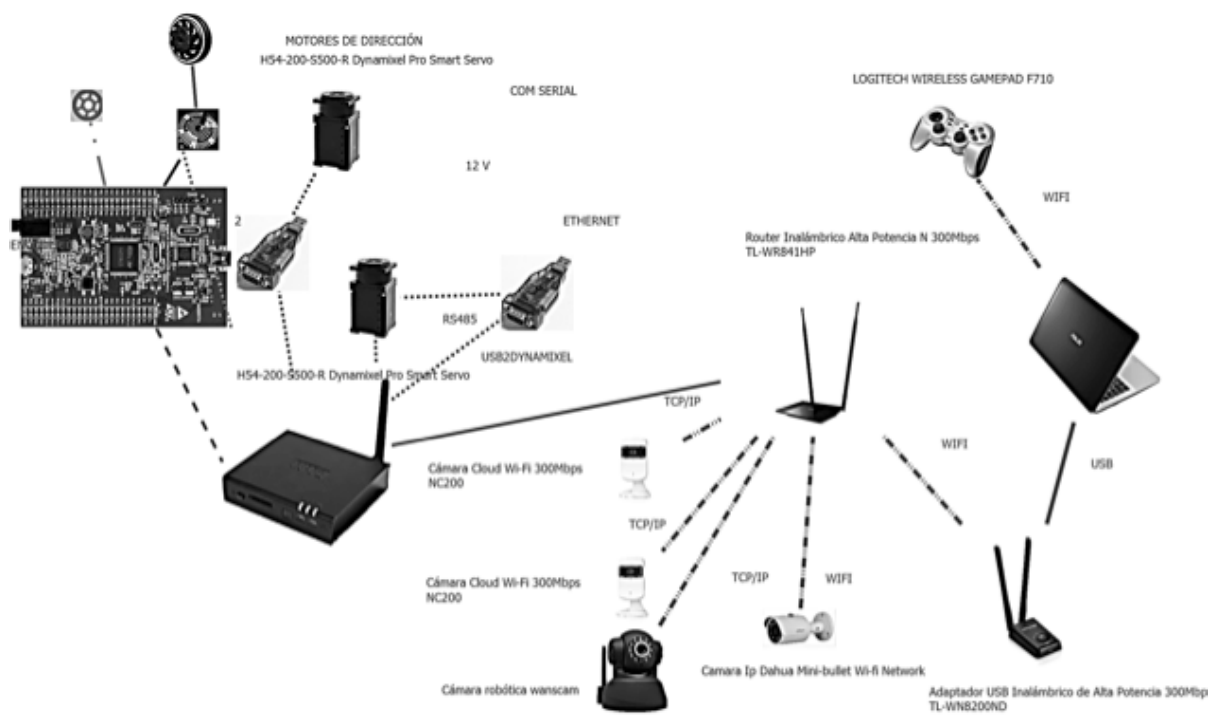

Fig. 9. Proposed electronic architecture

\section{Conclusions}

This work presented a proposed architecture for a mobile manipulator so that its elements are easy to acquire and low cost allowing it to be easy to repair and implement in a robot different from the one shown, this as a main advantage. The communication system is an important point in robot operation and a wireless system brings with it several disadvantages such as latency, signal dropping depending on the environment, limited operating range and high cost in specialized systems that help to solve these problems.

\section{Acknowledgements}

The research for this paper was supported by Nueva Granada Military University, through the project ING-IMP-2138

\section{$8 \quad$ References}

[1] P. M. Escobedo Castillo, "Manipulador Móvil: Estudio Sobre La Coordinación De Movimientos de un Manipulador Serial Acoplado," Ph.D. dissertation, UNAM, Mexico, 2012. [Online]. Available: http://www.ptolomeo.unam.mx:8080/xmlui/bitstream/ handle/132.248.52.100/1683/Tesis.pdf? sequence $=1$

[2] E. de Torres Rivera, "Implementación del Control Lateral Sobre un Vehículo con Dirección Asistida Eléctrica," Ph.D. dissertation, Universidad Carlos III de Madrid, Leganes, 2011. 
[3] "Springer Handbook of Robotics | Bruno Siciliano | Springer." [Online]. Available: http://www.springer.com/us/book/9783540382195

[4] M. W. Carey, E. M. Kurz, J. D. Matte, T. D. Perrault, and T. Padir, "Novel EOD robot design with dexterous gripper and intuitive teleoperation," in World Automation Congress (WAC), 2012, Jun. 2012, pp. 1-6.

[5] M. Fracchia, M. Benson, C. Kennedy, J. Convery, A. Poultney, J. W. Anderson, A. Tan, J. Wright, J. Ermilio, and G. M. Clayton, "Low-cost explosive ordnance disposal robot for deployment in Southeast Asia," in Humanitarian Technology Conference (IHTC2015), 2015 IEEE Canada International, May 2015, pp. 1-4. https://doi.org/10.1109/ IHTC.2015.7238055

[6] "La academia, con las botas puestas," Mar. 2015. [Online]. Available: http://www.elespectador.com/noticias/nacional/academia-botas-puestas-articulo-551287

\section{Authors}

Óscar F. Avilés S Was born in Bogotá, Colombia, in 1967. He received the Engineer degree in Electronics and Specialist of Electronic Instrumentation of Antonio Nariño University - UAN - in 1995 and 2002, respectively. Master in Automatic Production Systems - Technological University of Pereira - 2006 Colombia and PhD in Mechanical Engineering in Campinas State University - UNICAMP - Brazil. Currently is Professor in the Department of Mechatronics Engineering in Militar Nueva Granada University - UMNG. He has experience in the areas of Electronic Engineering, with emphasis on electronic instrumentation and control systems, acting mainly on the following topics: robotics, control and biomechatronics.

Mauricio F. Mauledoux M was born in Bogotá, Colombia, in 1982. He received the Engineer degree in Mechatronic engineering from the Militar Nueva Granada University, in 2005. In 2008 as a student of the Master in Information Technologies and Intelligent Systems in the St. Petersburg State Polytechnic University, Russia, at the automatic and intelligent distributed control department, he was promoted to a $\mathrm{PhD}$. In $2011 \mathrm{He}$ received the $\mathrm{PhD}$ degree in Mathematical models, numerical methods and software systems (Red Diploma) from the St. Petersburg State Polytechnic University, Russia. In 2012, he joined the Department of Mechatronic Engineering, at Militar Nueva Granada University, in Colombia, as an Assistant Professor. His current research interests include Robotics, automatic control, Multi-agent Systems, Smart Grids, and Optimization.

Oscar G. Rubiano M was born in Colombia in 1990. He studied his undergraduate in Militar Nueva Granada University where he received a degree in Mechatronics Engineering in 2013. He is a student of Mechatronics Engineering Master in Nueva Granada University. He has experience in the areas of modular robotics, mobile autonomous robotics and collaborative robotics

Article submitted 05 September 2017. Final acceptance 14 October 2017. Final version published as submitted by the authors. 